\title{
ANALISIS PENERAPAN KNOWLEDGE MANAGEMENT SYSTEM MENGGUNAKAN BOISOT AND I-SPACE MODEL
}

\section{(STUDI KASUS: POLITEKNIK POS INDONESIA)}

\author{
Roni Habibi ${ }^{1}$, \\ Program Studi D4 Teknik Informatika, Politeknik Pos Indonesia \\ E-mail: roni.habibi@poltekpos.ac.id 1. \\ Rizal Satria ${ }^{2}$ \\ Program Studi D4 Akuntansi, Politeknik Pos Indonesia \\ E-Mail:rizal.satria@poltekpos.ac.id ${ }^{2}$
}

\begin{abstract}
Abstrak
Politeknik Pos Indonesia merupakan perguruan tinggi vokasi yang komitmen terhadap penelitian, jurnal, karya ilmiah, data, dan dokumen penting lainnya. solusi dalam pengolahan dan penyediaan sistem informasi adalah dengan adanya sistem file sharing. File sharing digunakan untuk pegawai yang sudah melakukan penelitian, jurnal, pembuatan surat atau data penting lainnya lalu membagikannya. Penelitian ini untuk melakukan analisis perancangan knowledge management dengan acuan kerangka kerja Boisot And I-Space Model. Hasil kajian ini berupa analisis dan perancangan knowledge management. Dengan metode Boisot And I-Space Model menekankan bahwa pengetahuan dapat digeneralisasikan ke dalam situasi dan kondisi sesuai dengan studi kasus dengan tujuannya adalah untuk menghasilkan skema yang lebih baik yang memungkinkan aliran transformasi pengetahuan untuk dianalisis secara lebih rinci.

Dari hasil analisis dan perancangan knowledge management ini dapat di implementasikan dan di gunakan secara efektif dan efisien karena ketika ada pegawai yang membutuhkan data atau file akan mempermudah pencarian karena data atau file sudah tergabung dalam satu sumber daya.
\end{abstract}

Kata kunci: Knowledge Management, Teknologi Informasi, Metode Boisot And I-Space Model, Politeknik Pos Indonesia

\begin{abstract}
Politeknik Pos Indonesia is a is a vocational college committed to research, journals, scientific work, data, and other important documents. The solution in processing and providing information systems is a file sharing system. File sharing is used for employees who have done research, journals, making letters or other important data and then share it.

This study is to conduct an analysis of knowledge management design with a reference to the Boisot And I-Space Model framework. The results of this study are in the form of analysis and design of knowledge management. The Boisot And I-Space Model method emphasizes that knowledge can be generalized into situations and conditions by case studies to produce a better scheme that allows the flow of transformation of knowledge to be analyzed in more detail.

From the results of the analysis and design of knowledge management can be implemented and used effectively and efficiently because when there are employees who need data or files will facilitate the search because the data or files are incorporated in one resource..
\end{abstract}

Keywords: Knowledge Management, Information Technology, Boisot Method and I-Space Model, Politeknik Pos Indonesia

\section{PENDAHULUAN}

File sharing adalah komunikasi antar client dan server, agar client mendapatkan akses untuk melihat atau mendownload file. Client melakukan request dan server mengirimkan jawaban atas request yang dilakukan oleh client. Dengan file sharing yang biasa dilakukan, client akan terus menerus melakukan request kepada server, untuk mengupdate file yang diaksesnya. Ini akan membuat server maupun client 
selalu bekerja untuk melakukan komunikasi, sehingga sumber daya tersebut akan banyak terpakai untuk melakukan komunikasi itu, dan traffic dalam sebuah jaringan akan meningkat dengan aksi tersebut [9]. Salah satu solusi dalam pengolahan dan penyediaan sistem informasi adalah file sharing. File sharing digunakan untuk dosen atau pegawai yang sudah melakukan penelitian, pembuatan surat atau data lainnya kemudian membagikannya. Ketika ada pegawai yang membutuhkan data atau file akan mempermudah pencarian karena data atau file sudah tergabung dalam satu sumber daya.

Politeknik Pos Indonesia yang merupakan salah satu perguruan tinggi yang komitmen terhadap penelitian, jurnal, karya ilmiah serta data dan dokumen penting lainnya sehingga penting dengan adanya system informasi untuk mengelola data tersebut. Salah satu solusi dalam pengolahan dan penyediaan sistem informasi adalah file sharing tersebut. File sharing digunakan untuk pegawai yang sudah melakukan penelitian, jurnal, pembuatan surat atau data penting lainnya lalu membagikannya. Ketika ada pegawai yang membutuhkan data atau file akan mempermudah pencarian karena data atau file sudah tergabung dalam satu sumber daya.

Setelah mengumpulkan data-data yang sudah dianalisis, maka dapat dilakukan penerapan knowledge management system (boisot and i-space model). Model ini menekankan bahwa pengetahuan dapat digeneralisasikan ke situasi yang berbeda. Ini menghasilkan skema yang lebih baik yang memungkinkan aliran transformasi pengetahuan untuk dianalisis secara lebih rinci. Model ini juga menekankan pentingnya berbagi pengetahuan dengan sesama pegawai.

Analisis danerancangan dalam penelitian ini akan diuji pada studi kasus di unit Politeknik Pos Indonesia (Poltekpos). Model digunakana karena adanya penekanan bahwa pengetahuan dapat digeneralisasikan ke situasi yang berbeda sesuai dengan studi kasus, hal ini bertujuan untuk menghasilkan skema yang lebih baik yang memungkinkan aliran transformasi pengetahuan untuk dianalisis secara lebih rinci. Model ini juga menekankan terhadap pentingnya berbagi pengetahuan dengan sesama pegawai.

\section{METODE PENELITIAN}

Metodologi yang digunakan dalam melaksanakan penelitian ini adalah mengacu pada metodologi design science research sebagaimana dinyatakan oleh Peffers dkk. yang terdiri dari beberapa aktivitas seperti pada gambar 2.1.

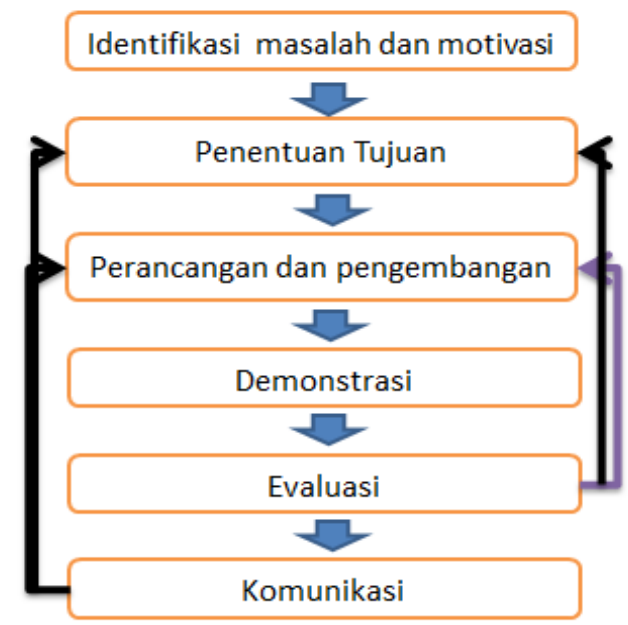

Gambar 2.1 Metodologi Penelitian (Peffers dkk, 2008)

Penjelasan tahapan dari gambar 2.1 adalah sebagai berikut:

\subsection{Identifikasi Masalah dan Motivasi}

Proses ini adalah persiapan dan perencanaan pelaksanaan penelitian. Proses ini terdiri atas beberapa aktivitas yaitu :

1. Mendefinisikan domain penelitian

Aktivitas pendefinisian domain penelitian dilakukan untuk menyatakan kegiatan (konteks) terhadap pihak terkait dalam objek di studi kasus.

2. Melakukan identifikasi masalah 
Aktivitas ini secara umum dapat dilakukan dengan melakukan studi pustaka atas penelitian yang telah dilakukan sebelumnya atau dari pengalaman pribadi. Identifikasi masalah ini dilengkapi dengan definisi lingkup dan batasan dan penelitian.

3. Melaksanakan studi pustaka

Studi pustaka dilakukan pada konsep-konsep yang terkait atau yang memiliki potensi keterkaitan dengan penelitian yang dilakukan.

4. Penentuan Tujuan

Tujuan penelitian dibuat dengan mengacu pada permasalahan yang telah didefinisikan sebelumnya yaitu merancang sistem informasi knowledge managament.

\subsection{Analisis}

Proses ini dapat memberikan gambaran keterkaitan dari masing-masing komponen dalam penelitian yang menjadi dasar dari proses selanjutnya yaitu perancangan. Proses analisis dimaksudkan untuk memahami pengetahuan dasar yang sudah ada dari hasil studi pustaka dan mengidentifikasi potensi yang ada untuk kepentingan penelitian.

\subsection{Perancangan dan Pengembangan}

Aktivitas-aktivitas dalam proses perancangan sistem informasi knowledge management ini adalah sebagai berikut :

1. Menentukan komponen model yang akan digunakan dalam perancangan sistem informasi knowledge manajemen.

2. Pembuatan use case diagram dimaksudkan untuk menggambarkan hubungan actor dengan sistem yang dikembangkan, sehingga dapat terlihat interaksi antara user dengan sistem melalui setiap use case. Setiap use case menggambarkan fungsi dari sistem yang akan dikembangkan berdasarkan pada user requirements yang telah dijelaskan dalam system yang dibuat sebelumnya.

3. Architecture Design dilakukan pembuatan Design criteria, Component diagram, dan Deployment diagram. Penentuan criteria dilakukan dengan maksud untuk membantu mengintegrasikan standar dan prosedur untuk menjamin kualitas sistem. component diagram bertujuan untuk menggambarkan pola arsitektur sistem yang dirancang. Setelah component diagram selesai dibuat, selanjutnya akan dibuat deployment diagram dengan menentukan pola distribusi data dari sistem yang dirancang.

\subsection{Demonstrasi}

Tahap ini bertujuan untuk melakukan penerapan perancangan yang telah dibuat untuk melihat sejauh mana rancangan tersebut dapat bermanfaat pada tempat studi kasus. Langkah-langkah yang dilakukan pada tahap demonstrasi ini adalah :

1. Penilaian terhadap kesesuaian model terhadap kebutuhan studi kasus.

2. Pengambilan data melalui wawancara, diskusi, kuisioner, brainstorming.

\subsection{Evaluasi}

Hasil dari tahap demonstrasi dievaluasi untuk mendapatkan keterangan mengenai perancangan yang dibuat. Apabila diperlukan maka dilakukan perbaikan terhadap rancangan sistem informasi knowledge management tersebut. Evaluasi ini dilakukan untuk mengetahui sejauh mana perancangan yang dibuat dapat memenuhi kebutuhan terhadap knowledge management.

\subsection{Komunikasi}

Tahap komunikasi merupakan tahapan pembuatan laporan hasil analisis, rancangan sistem serta hasil pengujian perancangan pada sebuah studi kasus.

\section{HASIL DAN PEMBAHASAN}




\subsection{Analisis}

Analis dan implementasi Boisot and I-space Model terhadap pembuatan aplikasi file sharing melalui tahapan-tahapan perencanaan pembuatan aplikasi file sharing :

\section{Scanning}

Menentukan perencanaan dan melakukan pemindaian terhadap data-data yang ada mengenai sistem yang akan dibangun berdasarkan kebutuhan pengguna. Dari hasil wawancara dan observasi bahwa pegawai menginginkan sistem aplikasi yang dapat menampung ilmu pengetahuan atau berbagi file antar pegawai agar memudahkan untuk saling berbagi pengetahuan satu dengan yang lainnya.

\section{Problem Solving}

Dari masalah-masalah yang ada, dimana Instansi membutuhkan sebuah inovasi untuk menampung berbagi pengetahuan yang dilakukan oleh pegawai. Dalam tahap ini adalah menentukan fitur-fitur yang terdapat dalam sistem aplikasi file sharing. Berikut daftar fitur-fitur yang akan terdapat di dalam sistem :

Tabel 3.1. Fitur Aplikasi File Sharing

\begin{tabular}{|c|l|l|}
\hline No & \multicolumn{1}{|c|}{ Fitur } & \multicolumn{1}{|c|}{ Keterangan } \\
\hline 1. & Tampilan Aplikasi & $\begin{array}{l}\text { Tampilan aplikasi bersifat user friendly agar mudah } \\
\text { digunakan oleh pengguna. }\end{array}$ \\
\hline 2. & Searching Pengetahuan & $\begin{array}{l}\text { Fitur searching pengetahuan diperlukan untuk memudahkan } \\
\text { pengguna dalam mencari file yang dibutuhkan. }\end{array}$ \\
\hline 3. & Kelola Pengetahuan & $\begin{array}{l}\text { Fitur kelola pengetahuan digunakan untuk mengelola file } \\
\text { yang telah dibagikan oleh pengguna dimana fitur ini hanya } \\
\text { dapat mengelola file berdasarkan data yang telah dibagikan } \\
\text { oleh masing-masing pengguna. }\end{array}$ \\
\hline 4. & Kelola Pegawai & $\begin{array}{l}\text { Fitur kelola data pegawai digunakan untuk mengelola data } \\
\text { pegawai yang dilakukan oleh admin dimana hanya admin } \\
\text { yang dapat menelola data pegawai. }\end{array}$ \\
\hline
\end{tabular}

\section{Abstraction}

Perancangan user interface dan fitur yang terdapat pada sistem aplikasi file sharing akan dinilai atau diuji sesuai yang dibutuhkan oleh pengguna (user friendly). Dengan melakukan wawancara dan penilaian skala $100 \%$, berikut hasil penilaian fitur-fitur yang terdapat pada sistem.

Tabel 3.2 Penilaian Fitur-Fitur

\begin{tabular}{|l|l|c|l|}
\hline No & $\begin{array}{l}\text { Fitur pada } \\
\text { Aplikasi }\end{array}$ & $\begin{array}{c}\text { Kepentingan } \\
(\boldsymbol{\%})\end{array}$ & \multicolumn{1}{|c|}{ Catatan } \\
\hline 1. & $\begin{array}{l}\text { Tampilan } \\
\text { Aplikasi }\end{array}$ & 90 & $\begin{array}{l}\text { Tampilan aplikasi bersifat penting karena akan } \\
\text { memudahkan dalam penggunaan sistem. }\end{array}$ \\
\hline 2. & $\begin{array}{l}\text { Searching } \\
\text { Pengetahuan }\end{array}$ & 85 & $\begin{array}{l}\text { Fitur ini penting karena untuk memudahkan pengguna } \\
\text { dalam mencari data ilmu pengetahuan }\end{array}$ \\
\hline 3. & $\begin{array}{l}\text { Kelola } \\
\text { Pengetahuan }\end{array}$ & 85 & $\begin{array}{l}\text { Fitur ini penting karena digunakan untuk mengelola file } \\
\text { pengetahuan yang telah atau belum dibagikan. }\end{array}$ \\
\hline 4. & $\begin{array}{l}\text { Kelola } \\
\text { Pegawai }\end{array}$ & 85 & $\begin{array}{l}\text { Fitur ini penting karena digunakan untuk mengelola data } \\
\text { pegawai. }\end{array}$ \\
\hline
\end{tabular}

\section{Diffusion}

Setelah menentukan fitur-fitur dan menilai seberapa pentingnya fitur, pada tahap ini dilakukan penentuan fitur yang akan didahulukan pembuatannya berdasarkan tingkat kepentingan pada fitur tersebut. Fitur dengan nilai kepentingan tertinggi akan didahulukan tahap pembuatannya dikarenakan fitur tersebut dibutuhkan segera mungkin sebelum fitur-fitur yang lain dibuat.

\section{Absorption}


Pada tahapan ini adalah tahapan yang menentukan waktu yang digunakan untuk membuat fiturfitur yang terdapat pada sistem apliksasi file sharing. Berikut waktu yang dibutuhkan dalam pembuatan fitur-fitur :

Tabel 3.3. Waktu Pengerjaan Fitur-Fitur Sistem

\begin{tabular}{|l|l|l|}
\hline No & Fitur & Waktu yang Ditentukan \\
\hline 1. & Tampilan Aplikasi & $8-15$ Hari \\
\hline 2. & Kelola Pegawai & $10-12$ Hari \\
\hline 3. & Kelola Pengetahuan & $5-8$ Hari \\
\hline 4. & Searching Pengetahuan & $4-6$ Hari \\
\hline \multicolumn{2}{|l}{ Jumlah Waktu yang Dibutuhkan } & $27-41$ Hari \\
\hline
\end{tabular}

\section{Impacting}

Impacting merupakan dampak yang akan terjadi setelah dibuatnya sistem aplikasi file. Dengan dibuatnya sistem aplikasi ini, semua kegiatan yang berkaitan dengan berbagi file akan mempunyai wadah atau resource untuk pegawai dalam melakukan proses file sharing.

Dalam tahap ini, pegawai tidak harus bertanya data hasil penelitian atau laporan-laporan yang diperlukan kepada pegawai lainnya secara langsung karena telah disediakan sistem aplikasi yang digunakan sebagai fungsi untuk berbagi dan mencari pengetahuan.

\subsection{Hasil Analisis Sistem}

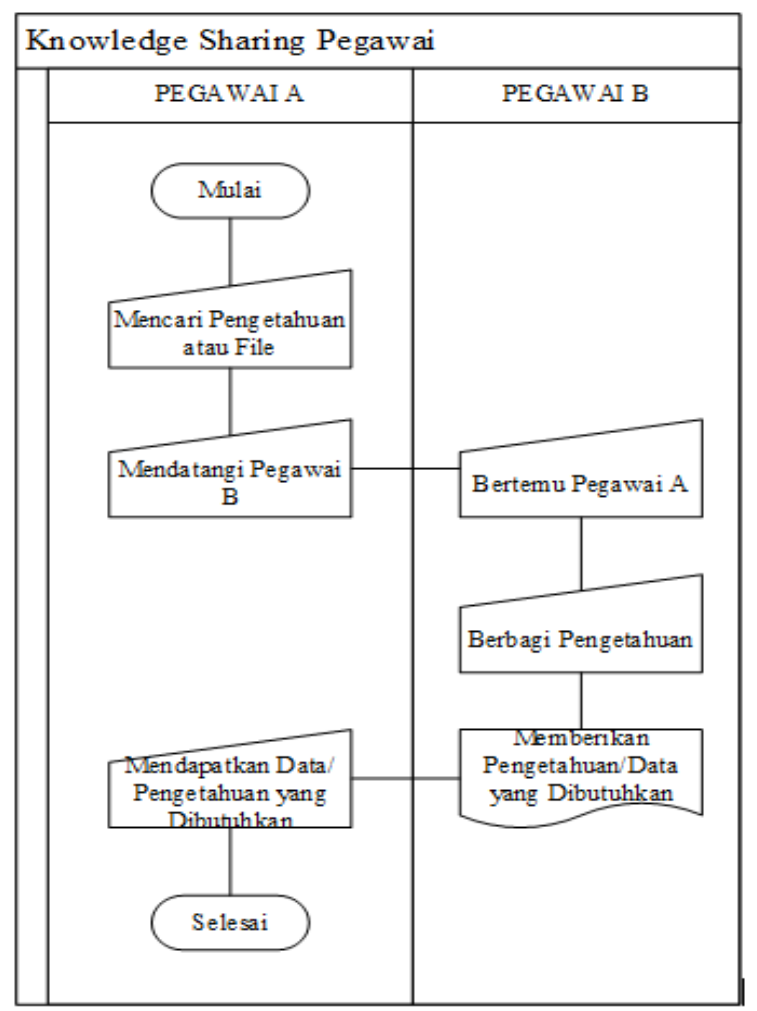

Gambar 3.1 Flowmap Sistem yang Sedang Berjalan

Keterangan system yang sedang berjalan gambar 3.1 di atas adalah :

1. Pegawai A mencari pengetahuan baru atau data/file.

2. Pegawai A mendatangi/menemui Pegawai B.

3. Pegawai B berbagi kepada Pegawai B tentang pengetahuan atau file.

4. Pegawai A mendapatkan pengetahuan atau file yang dibutuhkan dari Pegawai B. 


\subsection{Analisis Sistem yang Dibangun}

1. Proses Admin

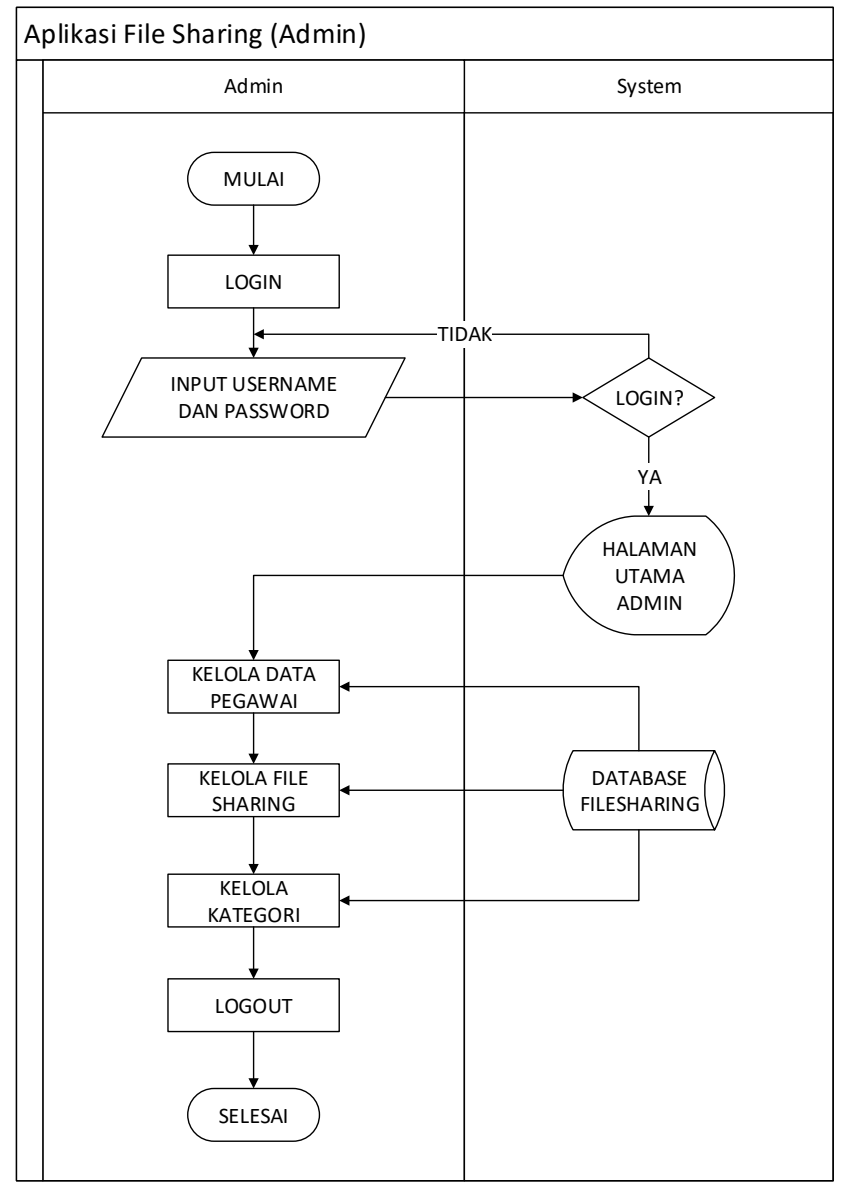

Gambar 3.2 Flowmap Sistem yang dibangun (Admin)

Keterangan:

1. Admin mengunjungi website file sharing.

2. Admin melakukan login ke halaman.

3. Setelah melakukan login, admin bisa melakukan kelola data pegawai dan kelola data file sharing serta kelola kategori.

4. Admin bisa melakukan aksi logout halaman website.

2. Proses Pegawai 


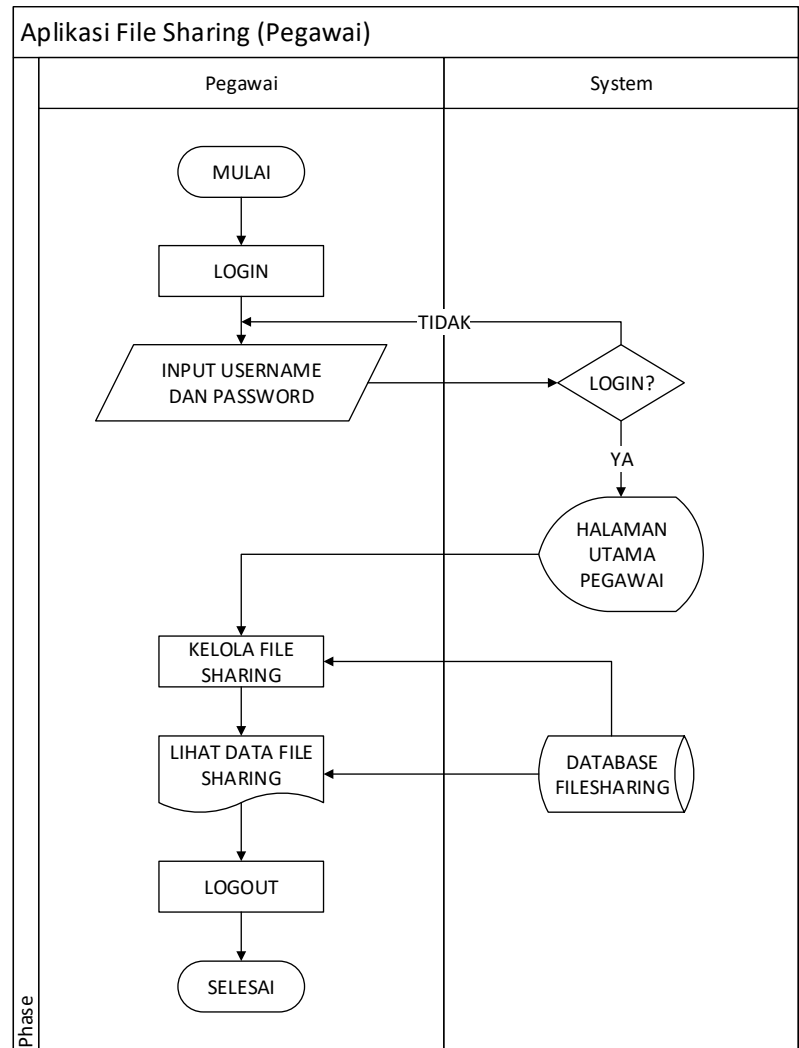

Gambar 3.3 Flowmap Sistem yang Dibangun (Pegawai)

Keterangan:

1. Pegawai mengunjungi website file sharing.

2. Pegawai melakukan login ke halaman.

3. Setelah melakukan login, pegawai bisa melakukan lihat file sharing dan kelola data file sharing.

4. Pegawai bisa melakukan aksi logout halaman website.

\subsection{Perancangan}

1. Use Case Diagram

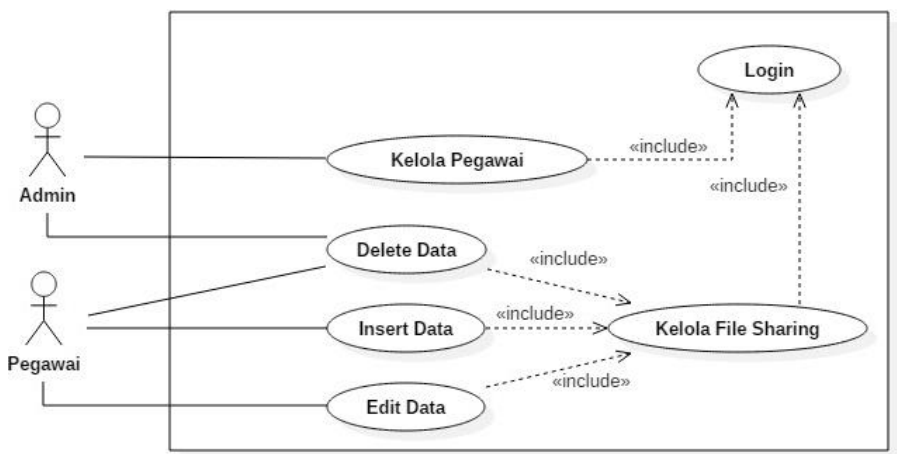

Gambar 3.4. Use Case Diagram File Sharing

Keterangan aktor dari gambar 3.4 didefinisikan dalam bentuk table dibawah ini:

Tabel 3.4 Definisi Aktor

\begin{tabular}{|l|l|l|}
\hline No. & \multicolumn{1}{|c|}{ Aktor } & \multicolumn{1}{c|}{ Keterangan } \\
\hline 1. & Admin & $\begin{array}{l}\text { Login, Kelola Data Pegawai, Kelola } \\
\text { Kategori dan Kelola File Sharing }\end{array}$ \\
\hline
\end{tabular}




\begin{tabular}{|l|l|l|}
\hline 2. & Pegawai & Login dan Kelola File Sharing \\
\hline
\end{tabular}

Tabel 3.5 Definisi Use Case (Admin)

\begin{tabular}{|l|l|l|}
\hline No. & \multicolumn{1}{|c|}{ Aksi } & \multicolumn{1}{c|}{ Keterangan } \\
\hline 1. & Login & Proses login ke halaman \\
\hline 2. & Kelola Pegawai & Melakukan kelola data pegawai \\
\hline 3. & Kelola Kategori & Melakukan kelola data kategori \\
\hline 4. & Kelola File Sharing & Melakukan kelola file sharing \\
\hline
\end{tabular}

Tabel 3.6 Definisi Use Case (Pegawai)

\begin{tabular}{|l|l|l|}
\hline No. & \multicolumn{1}{|c|}{ Aksi } & \multicolumn{1}{c|}{ Keterangan } \\
\hline 1. & Login & Proses login ke halaman \\
\hline 2. & Kelola File Sharing & Melakukan kelola file sharing \\
\hline
\end{tabular}

2. Deployment Diagram

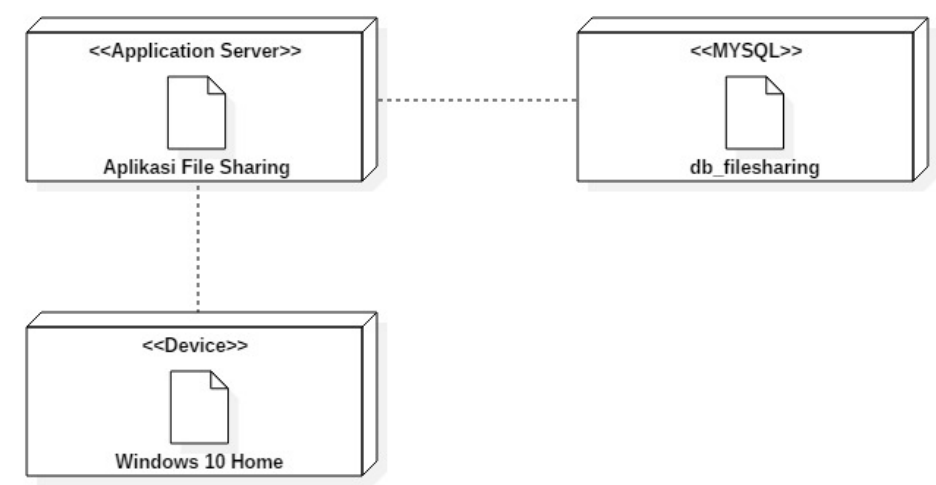

Gambar 3.5.Deployment Diagram

Deployment diagram pada gambar 3.5 adalah gambaran dari proses system dari hasil analisis yaitu system operasi yang digunakan oleh user adalah Microsoft windows 10 home, database yang digunakan adalah mysql dan aplikasi file sharing dengan Bahasa pemrograman PHP

3. Struktur Menu

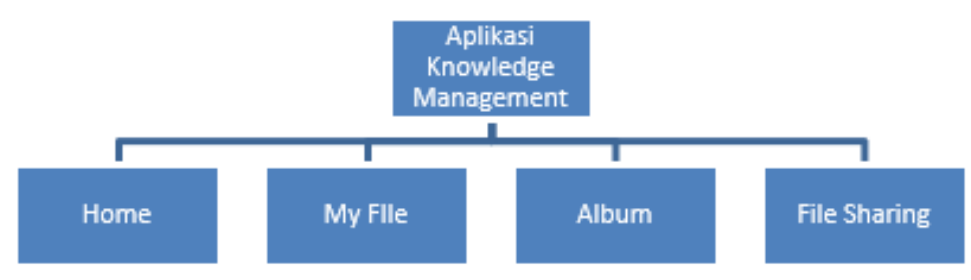

Gambar 3.5 Struktur Menu 


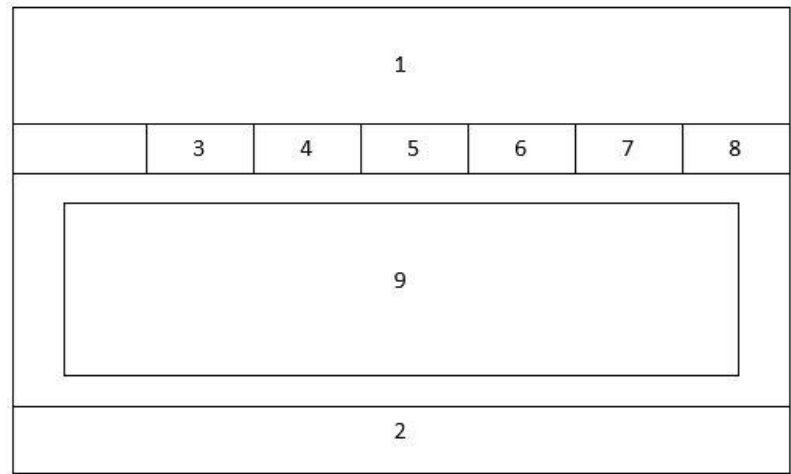

Gambar 3.6 Perancangan User Interface Home

Menu home diperlukan sebagai beranda dari sebuah aplikasi. Berikut penjelasan dari perancangan user interface home:
1. Header
6. Kategori
2. Footer
7. File Sharing
3. Home
8. Logout
4. My File
9. Tampilan Home
5. Album

\subsection{Evaluasi}

Evaluasi dilakukan dengan kuesioner, dapat diketahui bahwa sistem yang sedang berjalan, analisis dan perancangan dari hasil kuesioner yang telah di validasi bahwa kesesuaian dengan kebutuhan di Politeknik Pos Indonesia. Dengan Knowledge management ini apabila diimplementasikan merupakan langkah yang tepat dan sangat membantu mempermudah dalam penyampaian suatu informasi terbaru.

Evaluasi dari hasil analisis dan perancangan system adanya kesesuaian dengan model yang digunakan yaitu:

a. Data yang lebih mudah dapat terstruktur dan diubah menjadi informasi, semakin mudah terbaca.

b. Semakin sedikit data yang telah terstruktur sehingga memerlukan konteks.

Kemudian kesesuaian dengan Boisot model sebagai berikut:

a. Dari yang tidak dapat dikodifikasi menjadi dapat dikodifikasikan

b. Dari yang berwujud menjadi abstrak

c. Dari yang tidak dapat disebar menjadi dapat disebarkan

Hasil evaluasi dibuktikan dengan pengujian terhadap perancangan yang dilakukan seperti table 3.7 di bawah.

Tabel 3.7 Deskripsi dan Hasil Uji

\begin{tabular}{|l|l|l|l|l|}
\hline $\begin{array}{c}\text { Deskripsi Menu } \\
\text { Aplikasi }\end{array}$ & \multicolumn{1}{|c|}{$\begin{array}{c}\text { Prosuder } \\
\text { Pengujian }\end{array}$} & $\begin{array}{l}\text { Keluaran yang } \\
\text { diharapkan }\end{array}$ & $\begin{array}{c}\text { Kriteria } \\
\text { evaluasi hasil }\end{array}$ & \multicolumn{1}{c|}{$\begin{array}{c}\text { Hasil yang } \\
\text { didapat }\end{array}$} \\
\hline $\begin{array}{l}\text { Pengujian Login } \\
\text { (Admin) }\end{array}$ & $\begin{array}{l}\text { Masukan } \\
\text { username dan } \\
\text { password }\end{array}$ & $\begin{array}{l}\text { Tampilan } \\
\text { Halaman Utama }\end{array}$ & $\begin{array}{l}\text { Tampilan } \\
\text { Halaman } \\
\text { Utama }\end{array}$ & $\begin{array}{l}\text { Sesuai yang } \\
\text { diharapkan }\end{array}$ \\
\hline $\begin{array}{l}\text { Pengujian Login } \\
\text { (Pegawai) }\end{array}$ & $\begin{array}{l}\text { Masukan } \\
\text { username dan } \\
\text { password }\end{array}$ & $\begin{array}{l}\text { Tampilan } \\
\text { halaman utama }\end{array}$ & $\begin{array}{l}\text { Tampilan } \\
\text { halaman utama }\end{array}$ & $\begin{array}{l}\text { Sesuai yang } \\
\text { diharapkan }\end{array}$ \\
\hline $\begin{array}{l}\text { Pengujian Menu } \\
\text { Data Pegawai } \\
\text { (Admin) }\end{array}$ & $\begin{array}{l}\text { Data pegawai } \\
\text { pada bagian menu }\end{array}$ & $\begin{array}{l}\text { Tampilan } \\
\text { halaman data } \\
\text { pegawai }\end{array}$ & $\begin{array}{l}\text { Tampilan } \\
\text { halaman data } \\
\text { pegawai }\end{array}$ & $\begin{array}{l}\text { Sesuai yang } \\
\text { diharapkan }\end{array}$ \\
\hline
\end{tabular}




\begin{tabular}{|c|c|c|c|c|}
\hline $\begin{array}{c}\text { Deskripsi Menu } \\
\text { Aplikasi } \\
\end{array}$ & $\begin{array}{l}\text { Prosuder } \\
\text { Pengujian }\end{array}$ & $\begin{array}{c}\text { Keluaran yang } \\
\text { diharapkan }\end{array}$ & $\begin{array}{c}\text { Kriteria } \\
\text { evaluasi hasil }\end{array}$ & $\begin{array}{c}\text { Hasil yang } \\
\text { didapat }\end{array}$ \\
\hline $\begin{array}{lr}\text { Pengujian } & \text { Menu } \\
\text { File } & \text { Sharing } \\
\text { (Admin) } & \end{array}$ & $\begin{array}{l}\text { Data file sharing } \\
\text { pada bagian menu }\end{array}$ & $\begin{array}{l}\text { Tampilan } \\
\text { halaman data file } \\
\text { sharing }\end{array}$ & $\begin{array}{l}\text { Tampilan } \\
\text { halaman data } \\
\text { file sharing }\end{array}$ & $\begin{array}{l}\text { Sesuai yang } \\
\text { diharapkan }\end{array}$ \\
\hline $\begin{array}{lr}\text { Pengujian } & \text { Menu } \\
\begin{array}{l}\text { My } \\
\text { (Pegawai) }\end{array} & \text { File } \\
\end{array}$ & $\begin{array}{l}\text { my file pada } \\
\text { bagian menu }\end{array}$ & $\begin{array}{l}\text { Tampilan } \\
\text { halaman my file }\end{array}$ & $\begin{array}{l}\text { Tampilan } \\
\text { halaman my file }\end{array}$ & $\begin{array}{l}\text { Sesuai yang } \\
\text { diharapkan }\end{array}$ \\
\hline $\begin{array}{l}\text { Pengujian Menu } \\
\text { Album (Pegawai) }\end{array}$ & $\begin{array}{l}\text { Album pada } \\
\text { bagian menu }\end{array}$ & $\begin{array}{l}\text { Tampilan } \\
\text { halaman album }\end{array}$ & $\begin{array}{l}\text { Tampilan } \\
\text { halaman album }\end{array}$ & $\begin{array}{l}\text { Sesuai yang } \\
\text { diharapkan }\end{array}$ \\
\hline $\begin{array}{l}\text { Pengujian Menu } \\
\text { File Sharing } \\
\text { (Pegawai) }\end{array}$ & $\begin{array}{l}\text { file sharing pada } \\
\text { bagian menu }\end{array}$ & $\begin{array}{l}\text { Tampilan } \\
\text { halaman } \\
\text { sharing }\end{array}$ & $\begin{array}{l}\text { Tampilan } \\
\text { halaman } \\
\text { sharing }\end{array}$ & $\begin{array}{l}\text { Sesuai yang } \\
\text { diharapkan }\end{array}$ \\
\hline Pengujian Logout & $\begin{array}{l}\text { logout pada } \\
\text { bagian menu }\end{array}$ & Logout & Logout & $\begin{array}{l}\text { Sesuai yang } \\
\text { diharapkan }\end{array}$ \\
\hline
\end{tabular}

\section{KESIMPULAN}

Dari Analisis Penerapan Knowledge Management System Menggunakan Boisot And I-Space Model (Studi Kasus Politeknik Pos Indonesia), maka dapat ditarik kesimpulan bahwa Analisis dan Perancangan Penerapan Knowledge Management System Menggunakan Boisot And I-Space Model (Studi Kasus Politeknik Pos Indonesia) telah dibuat sesuai dengan yang diharapkan oleh pihak-pihak yang berkepentingan.

\section{REFERENSI}

Peffers, K., Tuunanen, T., Rothenberger, M. A., \& Chatterjee, S. (2007). A Design Science Research Methodology for Information System Research. Journal of Management Information Systems, 45-78.

Risal. M, 2013. Informasi Teknologi: Pengertian Teknologi Informasi.

Al Fatta, Hanif. 2007. Analisis dan Perancangan Sistem Informasi. Yogyakarta: Andi Offset.

Dalkir, K. 2011. Knowledge Management in Theory and Practice. USA: The MIR Press.

Hidajat, Jann. 2013. Personal Knowledge Management. Bandung: Institut Teknologi Bandung.

Maier, Ronald. 2007. Knowledge Management Systems Information and Communication Technologies for Knowledge Management. 3rd Edition. Springer. German.

Nasirin, Ahmad. 2015. Pengantar Teknologi Informasi. Semarang: Universitas Semarang.

Sholiq, 2006. Pemodelan Sistem Informasi Berorientasi Objek dengan UML. Yogyakarta: Graha Ilmu.

Prilanda, dkk. Implementasi Distributed File Sharing Dengan Pengumpulan Data File Secara Offline . 2010 